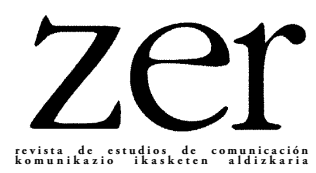

\title{
Representaciones de la inmigración latinoamericana en la cinematográfica española (1996-2008)
}

Latinoamerikako immigrazioaren irudikapenak Espainiako zinematografian (1996-2008)

Representations of the Latin American immigration in the Spanish cinematographic (1996-2008)

\author{
Maíra Dias Pereira ${ }^{\star}$ \\ Universidad Pública de Navarra
}

\begin{abstract}
RESUMEN: Este artículo interpreta las representaciones cinematográficas de la inmigración económica latinoamericana en España, entre 1996 y 2008. A través de un modelo de análisis socio-histórico del producto filmico, se utilizó el cine como manifestación de las representaciones sociales y de las expresiones ideológicas, y se estableció un diálogo con las contribuciones de los campos de la Historia, Sociología y de los Estudios Poscoloniales. En este proceso, el cine refleja una serie de aspectos sociodemográficos presentes en esta diáspora. Además, simultáneamente, denuncia los conflictos sociales presentes en este fenómeno migratorio y emite modelos estereotipados, propagando secuelas de un discurso hegemónico neocolonialista.
\end{abstract}

PALABRAS CLAVE: inmigración latinoamericana; Historia sociocultural del cine; representación social; ideología; discurso neocolonial.

LABURPENA: Artikulu honetan Espainian emandako Latinoamerikako immigrazio ekonomikoaren irudikapen zinematografikoak interpretatzen dira, 1996tik 2008 ra bitartean. Film produktuaren analisi sozio historikoaren eredu baten bidez, zinema gizartearen eta adierazpen ideologikoen irudikapenak agerian jartzeko erabili zen, eta harremana ezarri zen historia, soziologia eta kolonialismo ondoko ikasketen esparruekin. Prozesu honetan, zinemak diaspora horretan presente zeuden alderdi sozio demografikoak islatzen ditu. Horrez gain, aldi berean, migrazio fenomeno ho- 
rren baitako gatazka sozialak salatzen ditu eta eredu estereotipatuak ematen ditu, diskurtso hegemoniko neokolonialista baten ondorioak zabalduz.

HITZ GAKOAK: Latinoamerikako immigrazioa; zinemaren historia sozio kulturala; gizartearen irudikapena; ideologia; diskurtso neokoloniala.

ABSTRACT: This paper interprets the cinematographic representations of Latin American's, who for economic reasons immigrated to Spain, between 1996 and 2008. In line with the model of socio-historical analysis of the film product, cinema was used as a manifestation of social representations and ideological expressions, and a dialogue was established with the contributions of the fields of History, Sociology and Poscolonial Studies. In this process, the cinema reflects a series of socio-demographic aspects presents in this diaspora. In addition, simultaneously, it denounces the social conflicts present in this migratory phenomenon and emits stereotyped models, propagating sequels of a neocolonialist hegemonic discourse.

KEYWORDS: Latin American immigration; Socio-cultural history of cinema; social representation; ideology; neo colonial discourse.

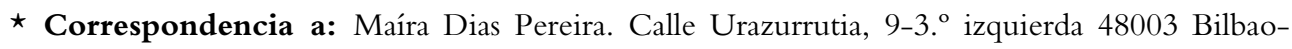
Vizcaya. mairalaranjeira2015@gmail.com

https://orcid.org/0000-0003-0399-1922

Cómo citar: Dias Pereira, Maíra. 2018. Representaciones de la inmigración latinoamericana en la cinematográfica española (1996-2008). Zer. 23(45). 13-33.

https://doi.org/10.1387/zer.19161

Recibido: 9 abril 2018; aceptado: 26 setiembre 2018

1137-1102 y 1989-631X / C 2018 UPV/EHU

(c) (1) Esta obra está bajo una licencia Creative Commons Atribución 4.0 Internacional 


\section{Introducción}

Durante el último cuarto del siglo xx y primer decenio del siglo xxI, el número de ciudadanos latinoamericanos residentes en España experimentó un fuerte incremento, llegando por primera vez en 2005 a consolidarse como el flujo migratorio extracomunitario más importante en el territorio español, por encima de las demás corrientes procedentes de los países del norte de África o del este europeo. De acuerdo con los datos proporcionados por el Padrones Municipales del Instituto Nacional de Estadística (INE), en 1998 los colectivos que procedían de algún país de América Latina ocupaban el tercer lugar y alcanzaban un $28 \%$ de la totalidad de la población extranjera en España, según continente de origen, y en 2008 ocupaban el primer lugar con aproximadamente un 40\% (Göttsch, 2010: 279-281). Los vínculos históricos y culturales, así como las transformaciones de las coyunturas socioeconómicas y políticas, tanto en los países de procedencia como en el país de acogida, contribuyeron a la intensificación de las corrientes de inmigración latinoamericana, dando lugar a un efecto de atracción, denominado "efecto llamada» por la prensa, para quienes tuvieron intención de emprender un proyecto migratorio, fundamentalmente ciudadanos en una situación de mayor vulnerabilidad en los procesos de inserción social y profesional en sus lugares de origen. Estos cambios generaron un gran impacto en la opinión pública, en las instituciones gubernamentales y privadas, y por supuesto en los medios de comunicación, entre los que se cuenta el cine.

En lo que se refiere al panorama cinematográfico español, a partir de la segunda mitad de la década de los noventa se observa un cambio de estrategia en la representación de lo latinoamericano. Esas imágenes revelan una fuerte tendencia a representar la inmigración económica procedente de América Latina y a emitir otros retratos de la otredad étnica, cultural e histórica latinoamericana. A partir de 1996 empiezan a ser rodadas las primeras producciones que otorgan a los latinoamericanos papeles protagonistas o relevantes en las narrativas filmicas. Se detecta una serie de cambios en materia de política migratoria en este período, caracterizado por la transición de legislatura del Partido Socialista Obrero Español al gobierno del Partido Popular, que pasa a gobernar por primera vez en el país. El año de 2008 es la fecha límite de este estudio, ya que la crisis económica y financiera internacional estalla y causa cambios en las características demográficas de la población investigada, ya que el proceso de integración de este colectivo en el mercado laboral español frena, y se produce entre la población inmigrante un aumento del retorno voluntario a los países de origen (Tedesco, 2010: 118).

Esta investigación sopesa las formas de representación de los latinoamericanos, que por motivos económicos inmigraron a España, en una selección de largo metrajes de ficción nacional producidos entre 1996 y 2008. Nuestra meta es analizar una selección de imágenes cinematográficas de la inmigración económica latinoameri- 
cana en España, que toman cuerpo, evolucionan y circulan entre 1996 y 2008; utilizar el soporte analítico del audiovisual como fuente documental e instrumento para cuestionar, reflexionar y comprender el contexto migratorio latinoamericano; y hacer uso del cine como testimonio histórico y socio-cultural, identificando las representaciones sociales y las expresiones ideológicas de una época.

\section{Metodología}

Para abordar este estudio manejamos el modelo cualitativo de análisis socio-histórico del producto filmico, de característica interdisciplinar y humanística, propuesto por Pierre Sorlin (1985), adaptándolo a las características de nuestra fuente filmica.

Con este instrumental examinamos el cine como manifestación de las representaciones sociales y de las expresiones ideológicas de un determinado tiempo y lugar, una de las perspectivas del sector de la Historia socio-cultural del cine. En este sentido, entendemos las representaciones cinematográficas como una fuente capaz de testimoniar y a la vez configurar la propia historia. Para ello, nos acercamos al panorama de la representación de lo latinoamericano en la cinematografia de ficción española, desde los primeros años del siglo xx hasta la primera década del siglo XXI. Así, constatamos que a partir de la década de los noventa hubo un cambio de retórica, y el cine pasó a interesarse por el tema de la inmigración económica. ${ }^{1}$

Con el objetivo de establecer una fuente documental fiable, registramos cuarenta y ocho películas que se ajustaban a nuestra delimitación temática: que fueran largometrajes de ficción, que presentaran protagonistas o personajes secundarios inmigrantes económicos latinoamericanos en España, y en el caso de que fueran coproducciones, que el capital mayoritario fuera español, y en cuanto a lo temporal, que fueran producidas entre 1996 y $2008 .^{2}$

A pesar de las especificidades de esta muestra global y de sus variaciones con respeto a las temáticas tratadas; así como a los modos de registrar el mundo circun-

1 En esta etapa, las obras de Santaolalla (2005), Elena (2005) y Monterde (2008) sirvieron como referencias fundamentales. A continuación, nos aproximamos a algunos factores del contexto político y socio-económico español del cambio de milenio que contribuyeron a la intensificación de las corrientes de inmigración latinoamericana, tomando como referencia a Juan B. Vilar (2002). Por último, investigamos sobre las producciones teóricas de una serie de autores de los campos de la Historia, de la Sociología y de los Estudios Poscoloniales, como Sorlin (1985), García Ballesteros, Jiménez Basco y Redondo González (2009), Göttsch (2010), Fanon (1968), Shohat y Stam (2002) y Hall (2010), estableciendo un diálogo con las imágenes filmicas en el marco analítico.

2 Ver Anexo. 
dante; a diferencias de género (que abarcan el drama, la comedia, la comedia dramática, la tragicomedia, la comedia romántica, la comedia negra, el realismo social, el thriller y el cine de aventuras); a diversidades en relación a las cualidades artísticas; a variaciones en relación a la complejidad que representa el personaje inmigrante; a si fueron pensados para un gran público o no; a si tuvieron más o menos éxito comercial, repercusión en los medios y en la academia, premios y proyecciones en festivales nacionales e internacionales de cine, etc., cabe mencionar que consideramos el cine de un período y de un lugar concretos como un conjunto de imágenes que poseen representaciones que se corresponden, que tienen caracteres comunes, y que manifiestan las expresiones ideológicas de una época.

A partir de estos datos, seleccionamos nueve filmes que tuvieran a inmigrantes latinoamericanos como protagonistas o en papeles de reparto destacados, y establecimos un corpus filmico que tuvo gran impacto social. De este modo, elegimos seis películas con mayor éxito comercial [Princesas (Fernando León de Aranoa, 2005), Sobreviviré (Alfonso Albacete y David Menkes, 1999), Flores de otro mundo (Icíar Bollaín, 1999), Cosas que dejé en la Habana (Manuel Gutiérrez Aragón, 1997), Pagafantas (Borja Cobeaga, 2009), y I love you baby (Alfonso Albacete y David Menkes, 2001)]; dos filmes que tuvieron una fuerte presencia en los festivales de cine, galardones cinematográficos y repercusiones en los medios de comunicación especializados [Rabia (Sebastián Cordero, 2010) y Ander (Roberto Castón, 2009)]; y una producción que generó muchas reflexiones en la producción académica sobre el tema del cine de inmigración en España [En la puta calle (Enrique Gabriel, 1996)].

Los aspectos que aquí se exponen sintéticamente proceden de la tesis de doctorado fue defendida el día 22 de marzo de 2017, en la Universidad Pública de Navarra (UPNA), siendo su director el doctor Juan Madariaga Orbea. Es importante mencionar que esta investigación doctoral fue financiada con la ayuda de formación del personal investigador, concedida por la UPNA, entre los años de 2012 y 2015.

\section{Análisis del discurso fílmico}

\subsection{Breve EXAMEN DE LA MUESTRA AMPlificAda}

El análisis de las 48 películas que componen nuestra muestra global nos permitió reconocer algunas características que hemos considerado importantes para acercarnos a una representación más global del panorama de la inmigración económica latinoamericana en España, como los tipo de personaje (secundario o protagonista), tiempo que están en España, repartición territorial, composición por nacionalidad, género, estado civil, descendencia, franja de edad, repartición en el mercado laboral español y acceso a la documentación para residir y trabajar en el país. 
De esos 109 personajes, 83,48\% son secundarios, mientras que 16,51\% son protagonistas. Es interesante mencionar que algunas películas presentaron personajes secundarios que se destacaron, como fue el caso de $3.66 \%$ de la totalidad de la muestra.

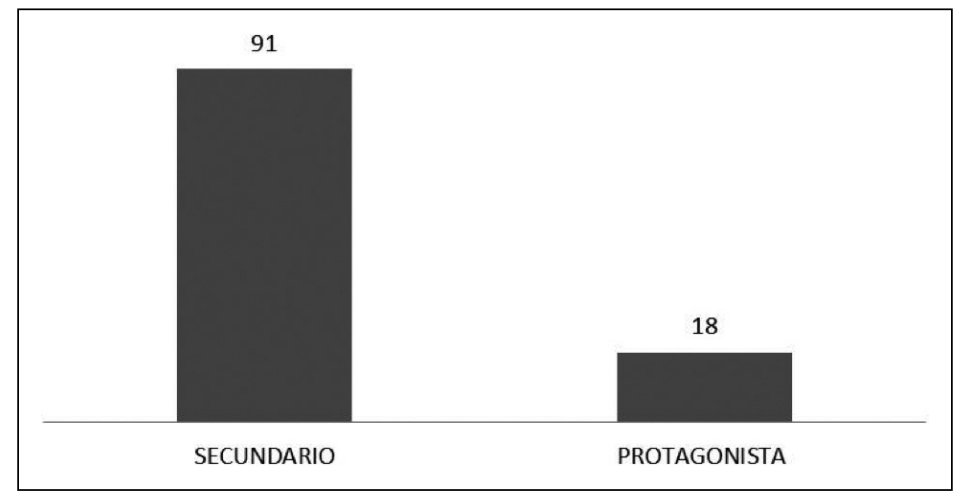

Tipo de personaje

La mayoría de los personajes son representados como ciudadanos recién llegados, constituyendo un 11,92\% de la muestra total, 1,83\% de los personajes llegaron seis meses antes, 0,91\% llegaron entre 6 meses y un año antes, 3,66\% entre uno y cinco años antes y $0.91 \%$ llegaron a España desde hace más de cinco años.

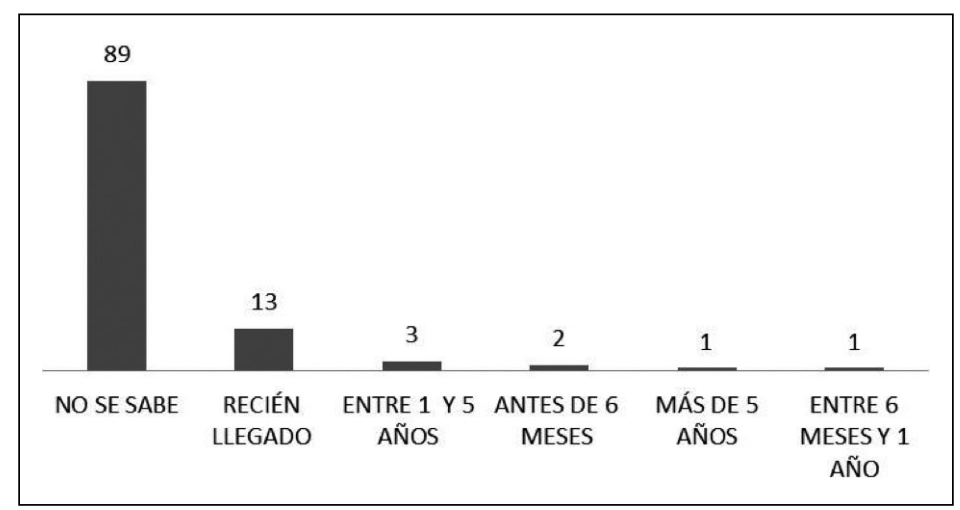

Tiempo que llevan en España

En cuanto a la cuestión de la distinción territorial, concluimos que el mayor porcentaje de los personajes de la muestra fueron representados en núcleo urba- 
nos. La mayoría de las películas, un 66,90\%, transcurre en Madrid, 4,16\% tiene la ciudad de Bilbao como escenario, 2,08\% de las películas sucede en Barcelona, y la misma cifra en Hospitalet de Llobregat, en Cantalojas, en algún pueblo de Castilla y la Mancha, Gijón, en algún pueblo de la cuenca asturiana, en algún pueblo del Valle de Arratia, en Bidania, en Burgos, en algún pueblo de la Ribera Alta, en Alicante, en Cullera, en Puerto Hurraco, en Cáceres, en algún pueblo de Murcia, en Betanzos y en La Coruña. Si repartimos la acción de las películas por Comunidades Autónomas, un 60,41\% ocurre en la Comunidad de Madrid; un 8,33\% en el País Vasco, un $6,25 \%$ en la Comunidad Valenciana, un 4,16\% en Catalunya, Galicia, Extremadura, Castilla y La Mancha y en el Principado de Asturias, y el 2,08\% en Castilla y León y Murcia.

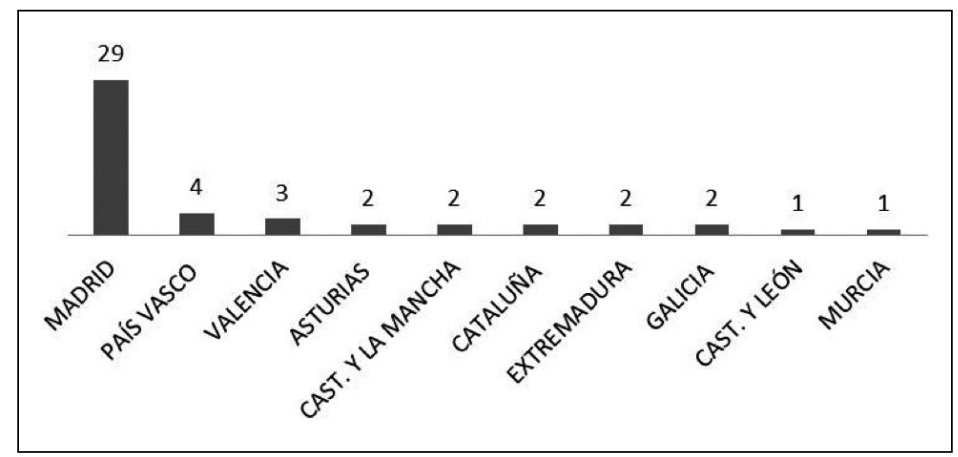

Comunidad autónoma en la que transcurre la película

En relación a las composiciones por nacionalidad, vimos que la mayoría de los personajes proceden de Cuba, totalizando un 36,69\% del total de la muestra, mientras que 20,18\% de República Dominicana, 12,84\% de Perú, 13,76\% de Argentina, 6,42\% de Colombia, 1,83\% de Puerto Rico, 1,83\% de Brasil, 0,91\% de Honduras, la misma cifra representó los ciudadanos de Méjico, y 4,58\% son personajes provenientes de algún país andino que no podemos identificar. Es evidente que el cine privilegia la representación de personajes de la región caribeña, puesto que un 58,7\% de la muestra son procedentes de allá, frente a un $17,42 \%$ que son de origen del área andina, $14,67 \%$ provienen del cono sur, $6,42 \%$ son de origen colombiano y $1,83 \%$ proceden de la zona central del continente. 


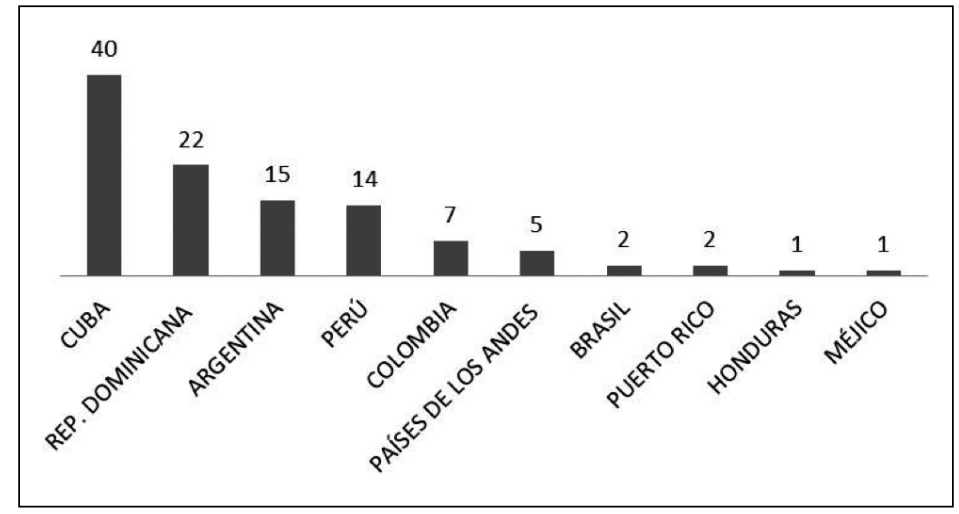

País de origen

Sobre la composición por género, vimos que hay un número más elevado de mujeres - representan un 55,96\% de la muestra - que de hombres, que constituyen un 44,03\%. La proporción por género en relación a los protagonistas y los secundarios son equilibradas en estas cifras, ya que un 55,55\% de los protagonistas son mujeres, mientras que un $44,44 \%$ son hombres, y un $56,04 \%$ de los secundarios son del género femenino y $43,95 \%$ son del género masculino.

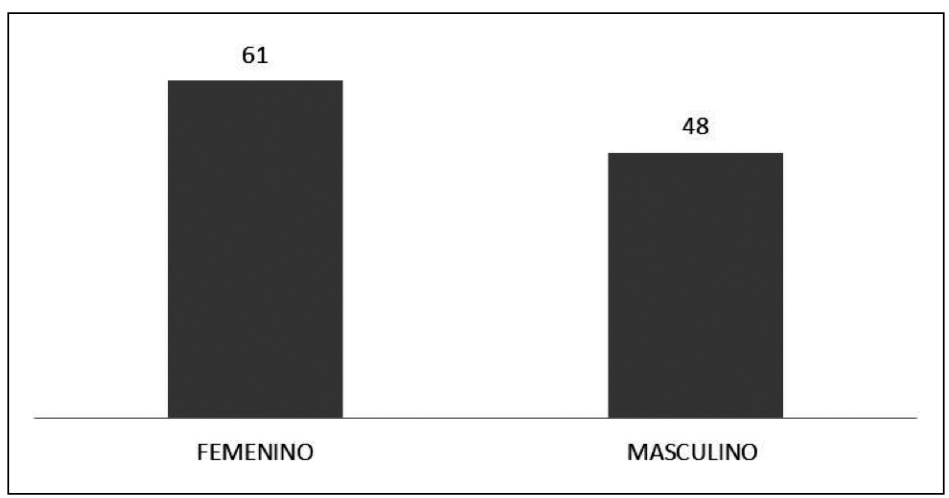

Género

En relación a la franja de edad, verificamos que la mayoría de los personajes latinoamericanos son representados entre los treinta y los treinta y nueve años, siendo un $42,20 \%$ de la muestra, seguidos de la franja de edad de los veinte un $33,02 \%$, de los cuarenta un $15,59 \%$, de los cincuenta un $6,42 \%$ y de los sesenta un $2,75 \%$. Vimos que las poblaciones muy jóvenes y las más mayores son poco representadas. Si 
incluimos los niños latinoamericanos que acompañan a estos personajes adultos, la franja de edad entre 0 y 10 años corresponde a un 6,60\%. La mayoría de la muestra se trata de adultos jóvenes, entre los veinte y los cuarenta años.

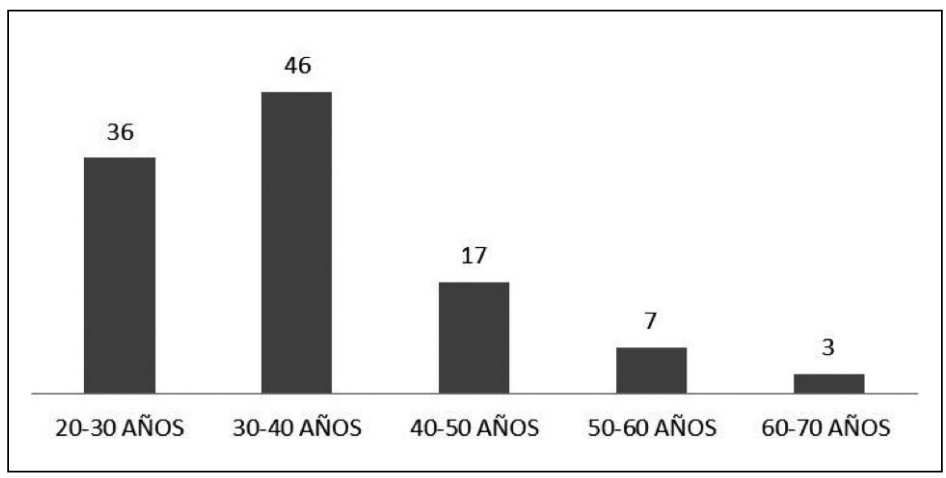

Edad

Cuando nos acercamos al tema del estado civil, detectamos que un 35,77\% de los personajes están casados o tienen algún tipo de relación de pareja, mientras que un $9,17 \%$ son representados como ciudadanos solteros o que no tienen ningún tipo de pareja.

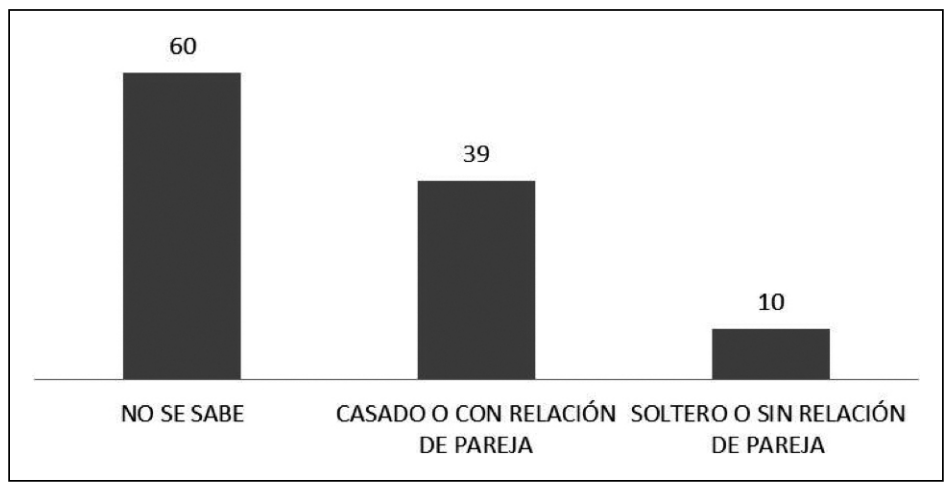

Relación de pareja

Un 56,41\% están casados o tienen alguna relación de pareja con un paisano, no obstante, un 59,09\% de esas relaciones no prosperan. Por otro lado, un 43,58\% están casados o tienen alguna relación de pareja con un autóctono, y sin embargo, apenas $29,41 \% \%$ de esas relaciones fracasan. 


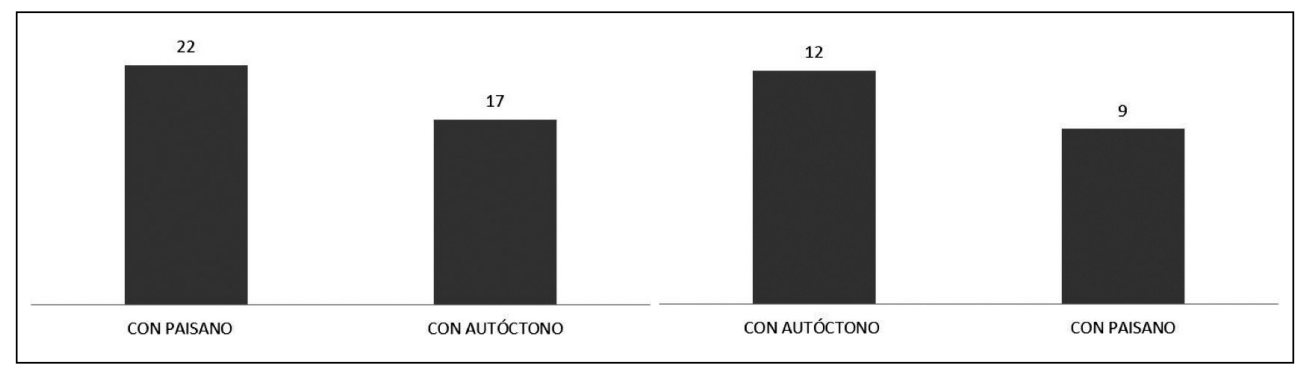

Tipo de relación de pareja

Constatamos que un $16,51 \%$ de la muestra no tienen hijos, mientras que un $11 \%$ los tienen. De estos, un $25 \%$ han tenido que dejarlos en sus países de origen, y un 75\% viven con ellos en España. Un 6,42\% del total de la muestra están a punto de ser madres y padres en el nuevo país. Vemos que las cifras más altas corresponden a los latinoamericanos que son claramente representados con descendentes. Vemos que una cifra muy baja tienen otros familiares en el país, un 8,25\% de la muestra.

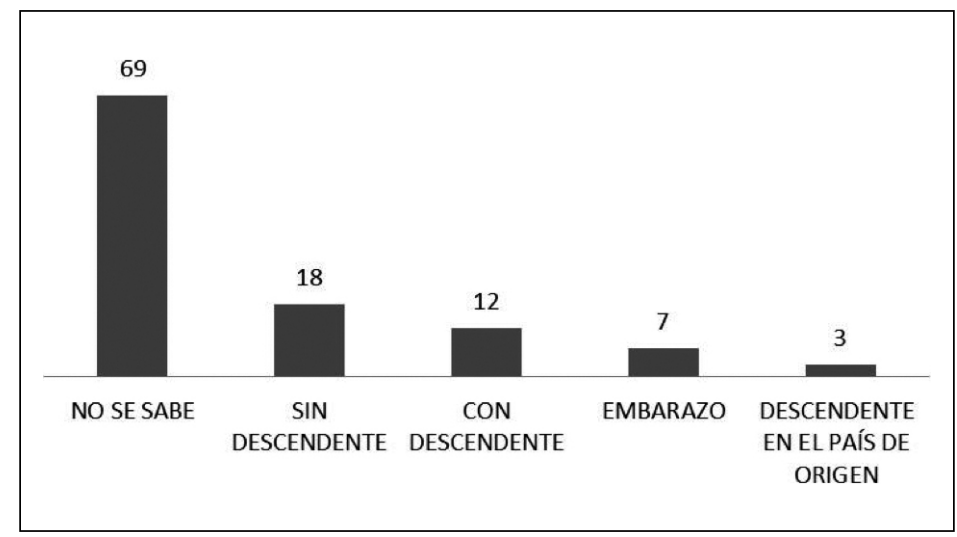

\section{Descendencia}

Sobre el tema del reparto en el mercado laboral español, identificamos que hay cierta diversidad de profesiones, a pesar de que la gran mayoría trabaja en el sector terciario (servicios), como los trabajadores en el área de la hostelería, representados con un 13,76\% - que incluyen camareros, camareros de barra, cocineros y encargados-, los empleados de hogar, con un 12,84\% — que incluyen a los que realizan tareas generales de hogar, limpieza y a los que trabajan en la atención a dependientes-, los músicos, con un 12,84\%, los que trabajan como 
esteticistas o peluqueros, con un 4,58\%, los propietarios de bar/ restaurante, los atletas, las actrices, que son representados con un $1,83 \%$ y las ocupaciones que cuentan con una cifra de $0,91 \%$, como el propietario de peluquería, la dependienta en una peletería, el encargado de locutorio, el animador en fiestas infantiles, la bailarina en una casa de alterne, el dramaturgo, el informático, la diseñadora gráfica, la secretaria, el ayudante en mudanzas, el vendedor de patatas y la empleada de limpieza en empresa. Algunos de los inmigrantes latinoamericanos realizan tareas que se relacionan con el sector de la construcción y de la industria, como los albañiles, con un $6,42 \%$, los que trabajan en talleres de peletería, con un $2,75 \%$, los que trabajan como obreros en fábricas, que son un $1,83 \%$, el encargado de fábrica, un $0,91 \%$, la propietaria del taller de pieles y tienda, un $0,91 \%$.

Vemos que son muy pocos los que desarrollan sus trabajos en el sector primario (agricultura y pecuaria), pues sólo 1,83\% realizan tareas en el área rural. Podemos observar que en algunos casos los personajes ejercen simultáneamente un empleo o más, o que cambian continuamente de trabajo. Subrayamos que la mayor cifra de los inmigrantes económicos latinoamericanos que son representados trabajando en España corresponde a los personajes que ejercen la prostitución, siendo un 16,51\% del total de las actividades profesionales. También vemos que algunos inmigrantes desempeñan tareas laborales que están relacionadas con el mundo de la delincuencia, como el 1,83\% que trafican con pasaportes y visados, y el $0,91 \%$ que trafica con puros y obras de arte.

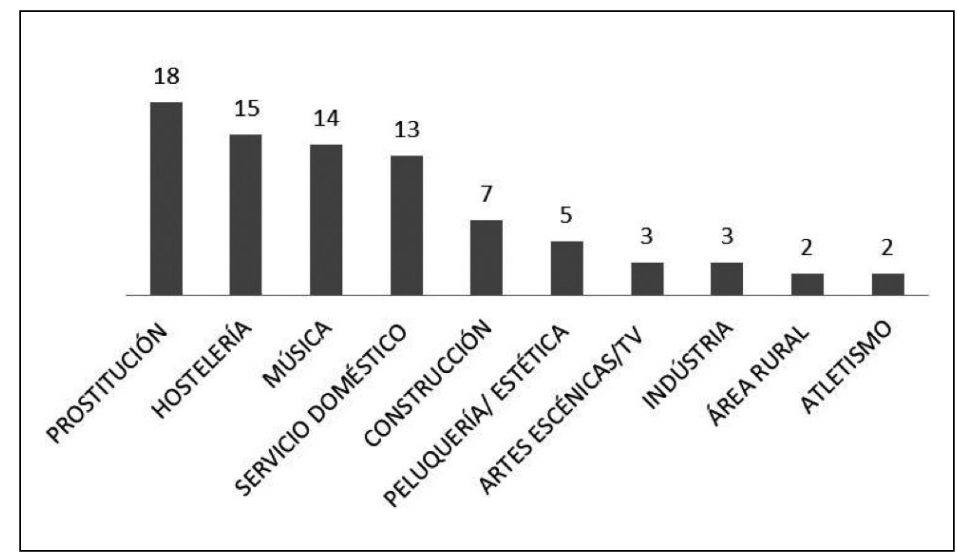

Área laboral más frecuente

Sobre la temática de la irregularidad laboral, vimos que el 38,53\% de la muestra no tiene la documentación para residir y trabajar legalmente en el país, mientras que 
un $22,93 \%$ la tienen. De los que consiguieron los documentos, vemos que $20 \%$ accedieron a los papeles gracias al matrimonio de conveniencia, un $8 \%$ a través del casamiento con personas españolas, un $12 \%$ por medio de la descendencia española o europea, y apenas un $4 \%$ a través de una oferta de trabajo.

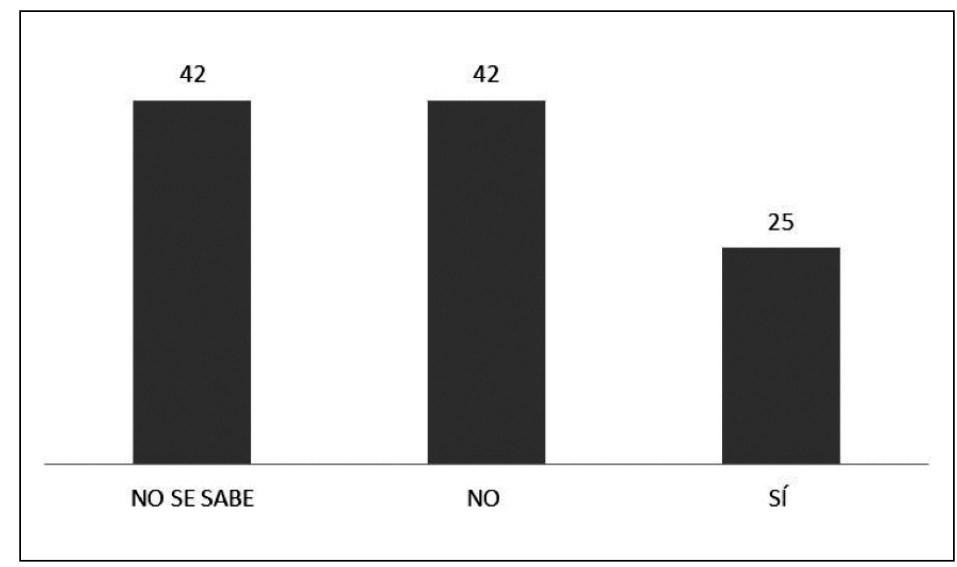

Permiso de residencia y trabajo

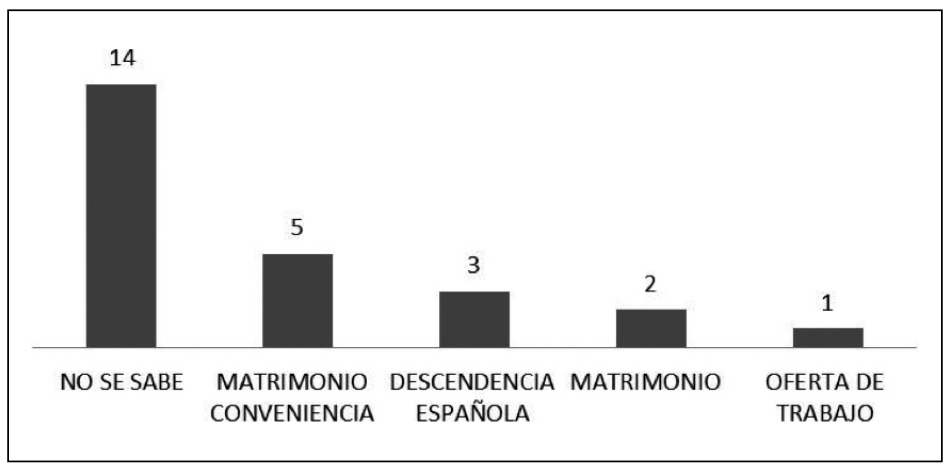

Cómo se obtienen el permiso de residencia y trabajo

\subsection{Un ACERCAMIENTO AL CORPUS Fílmico}

\subsubsection{Datos sobre el perfil sociológico y psicológico del inmigrante cinematográfico}

Observamos que las características halladas en la muestra global de 48 películas repiten las mismas tendencias presentes en la representación cinematográfica de este colectivo que aparecen en nuestro corpus filmico, y por eso nos pareció más interesante ade- 
cuarnos a los principios metodológicos propuestos por Sorlin (1985), seleccionando y delimitando una serie de nueve películas, y finalmente iniciando un análisis cualitativo que nos permita profundizar un conjunto de discursos y aproximarnos al paradigma de la representación del inmigrante económico latinoamericano en España.

Al analizar la evolución de los flujos migratorios de estas poblaciones en España, según, por ejemplo, el reparto geográfico, la nacionalidad, el género, la edad y la distribución por áreas laborales, contemplamos como nuestro corpus fílmico puede estar vinculado con las características socio-demográficas de la época. Este conjunto de representaciones sociales revelan diversos fenómenos presentes en esta diáspora, como son los casos de las imágenes que abordan las historias de personajes representados en el espacio urbano y mayoritariamente en Madrid; de género femenino; adultos jóvenes que se ubican en la franja de edad que va de los 20 a los 39 años y que están en una edad activa para la incorporación al mercado de trabajo y para la procreación; que ocupan áreas laborales del sector terciario, con altas cifras de irregularidad y marcados por la estratificación laboral por etnia y género, ejerciendo, sobre todo, actividades relacionadas con el servicio doméstico, ocupándose de mantener la infraestructura y la limpieza del hogar, o de atender a personas dependientes, y también del área de la hostelería; que envían remesas de dinero; que reagrupan sus familiares; que fueron motivados por alejarse de los conflictos socio-económicos de sus países de origen, etc., como destacan los estudios sociológicos realizados por García Ballesteros, Jiménez Basco y Redondo González (2009), y Göttsch (2010).

Es interesante resaltar que, en general, el corpus fílmico representa ciudadanos que se identifican con los grupos étnicos afrodescendientes y autóctonos de América Latina, presentando un mayor interés narrativo por las historias de la población caribeña, provenientes de la República Dominicana y de Cuba. Los personajes procedentes de Perú, Colombia y Argentina, empiezan a ser representados con más frecuencia a partir de 2008, a pesar de que ya presentaban altas tasas migratorias desde los primeros años del siglo XXI en España. Es muy significativa la ausencia de representaciones de otras nacionalidades, como la ecuatoriana, que ya tenía un peso poblacional, desde el año 2000, como destaca Elena (2005). De alguna manera, el cine refleja el fenómeno del importante incremento de las poblaciones procedentes de los Andes, y de la disminución de la población llegada del Caribe, a partir de los primeros años del siglo xxi, una tendencia detectada en la evolución de las cifras estadísticas. El alza de las poblaciones procedentes de Ecuador, Colombia y Bolivia, y el descenso de los procedentes de República Dominicana y Cuba, dos países con altas tasas migratorias en la década de los noventa, es notable (García Ballesteros, Jiménez Basco y Redondo González, 2009: 57).

Observamos que muchos de los personajes masculinos son ventajistas, irresponsables, inmorales, promiscuos, poco centrados en el trabajo y con cierta tendencia a delinquir y a abandonar sus descendentes, como se refleja en Cosas que dejé en la Habana, 
Flores de otro mundo y I love you baby. Por su parte, los femeninos son mayoritariamente gente íntegra y honesta. Pero cuando las circunstancias les obligan pueden ser astutas y oportunistas, con el fin de mantenerse económicamente o adquirir los documentos para residir y trabajar, como vemos en Cosas que dejé en la Habana, Flores de otro mundo y Pagafantas. Igualmente, cuando tienen una relación desinteresada con el cónyuge español, algunos de estos personajes manifiestan cierta dependencia laboral y financiera. En general, los personajes son generosos, optimistas, alegres, benevolentes, extrovertidos, habladores, y dinámicos, tanto mujeres como hombres. Sin embargo, los provenientes de Perú y Colombia, todos de ascendencia indígena, poseen un carácter introvertido, discreto y tímido. Mayoritariamente los personajes latinoamericanos son adaptables, perseverantes, laboriosos, subordinados, amables, emotivos y pasionales. Generalmente también son atractivos, sexualmente activos, y de muchas veces se relacionan con el universo de la prostitución, es decir, son tratados en términos fetichistas, como observamos en Cosas que dejé en la Habana, Flores de otro mundo y Sobreviviré.

En lo que se refiere a los paisajes urbanos y rurales, a los espacios públicos y privados, a las zonas de ocio, residenciales y socio-profesionales, identificamos qué espacios diferenciados fueron modificados por la presencia del fenómeno migratorio en España y cuáles son las representaciones de las divisiones topográficas de la inmigración latinoamericana en España emanadas por este cine. De este modo, constatamos que las representaciones de estos ciudadanos en organizaciones no gubernamentales, en cooperativas, asociaciones, manifestaciones callejeras, bibliotecas, universidades, centros de enseñanza, centros de cultura, museos, cines, conciertos, espectáculos de danza, lugares emblemáticos de interés turístico y cultural, partidos de futbol, corridas de toros, fiestas populares, montes, jardines, parques, gimnasios, centros comerciales, tiendas de ropa, etc. son inexistentes.

En general, tienden a ser representados como ciudadanos católicos, heterosexuales, castellano hablantes, con escasa cualificación profesional y académica, y caracterizados por la falta de ambición para estudiar o cambiar de área profesional. Esos personajes casi no revelan interés por actividades intelectuales, artísticas, políticas o deportivas. Su tiempo de ocio y sus hábitos de consumo están muchas veces relacionados con ciertos tipos de música, baile, alcohol y alimentación, como por ejemplo, frecuentar bares con danza, bailar salsa, bachata, merengue, beber mojito, ron, comer comidas típicas locales, etc. Además, constatamos que casi no hay imágenes que revelan el sincretismo entre las culturas nativas, africanas y europeas, o reflexiones sobre las relaciones existentes entre las migraciones y el colonialismo.

\subsubsection{Desafíos, conflictos y principales metas en el proyecto migratorio}

Este colectivo afronta una serie de desafios en el país de acogida, que les obstaculizan su integración social y que les impide realizar dignamente sus proyectos migra- 
torios. Mencionamos las limitaciones para la incorporación del latinoamericano en el mercado de trabajo. Esta población está más sujeta a las estratificaciones laborales por género y etnia, teniendo una mayor propensión a acceder a ocupaciones deficientes cualificadas y precarias (Göttsch, 2010: 288), como apreciamos en En la puta calle, Flores de otro mundo y Rabia. En este sentido, muchos de los personajes del corpus fílmico ejercen trabajos caracterizados por la irregularidad, la ausencia del respaldo de las leyes gubernamentales que rigen los convenios laborales, la falta de apoyo de los sindicatos laborales, la inestabilidad, la temporalidad, las extensas horas de trabajo, los bajos sueldos, y los abusos por parte de los empleadores, que pueden despedir injustificadamente o tratar al empleado de forma humillante. Además de esto, las políticas públicas migratorias de control generan grandes obstáculos a la hora de acceder a los permisos de residencia y trabajo, reflejando la escasez de proyectos gubernamentales de integración social que favorezcan la igualdad socio-económica, política y de derechos de ciudadanía entre latinoamericanos y españoles. Otras representaciones revelan los conflictos asociados con las políticas de seguridad y de frontera relacionadas con la vigilancia y el acoso del cuerpo policial, como vemos en En la puta calle, Princesas y Pagafantas. Esto da lugar a una mayor exposición a situaciones de violencia, sobre todo si se trata de inmigrantes del género femenino, como se refleja en Sobreviviré, Princesas y Rabia. La dificultad para superar la pobreza y ascender socialmente son otras de las problemáticas abordadas. También citamos los choques culturales, como vemos en Flores de otro mundo, y los efectos doctrinarios del sistema colonialista en el discurso y en las prácticas cotidianas, que revelan las actitudes racistas, eurocéntricas y sexistas que marginan esta población por su origen, cultura, color de pie o clase social. Algunos personajes del país de acogida creen que los latinoamericanos son perezosos, vagos, poco laboriosos, tramposos, caóticos, incivilizados, culturalmente retrasados, ventajistas, salvajes y libidinosos, como observamos en En la puta calle, Flores de otro mundo y Princesas. La otredades provenientes de las sociedades colonizadas también experimentan un sentimiento de alienación de su propia identidad. De esta forma, estos ciudadanos subestiman sus propios rasgos étnicos, lingüísticos y culturales, y sobrevaloran el mundo del colonizador, como vemos en En la puta calle, Cosas que dejé en La Habana y I love you baby. Otras situaciones que no facilitan el proceso migratorio son la ausencia de soporte afectivo, que se refleja en las historias de soledad y añoranza de los familiares, amigos y antiguas parejas, o la falta de una red dinámica de vínculos sociales, como se aprecia en Flores de otro mundo, Sobreviviré y Princesas.

Por otro lado, este cine también emite las estrategias que esta población utiliza para superar algunos de esos retos. El corpus fílmico revela una serie de movimientos al representar las rearticulaciones entre sus culturas originales y las culturas autóctonas, en las tentativas de integración en el nuevo entorno socio-cultural. Hallamos imágenes que reflejan la creación y frecuentación de espacios socio-culturales transnacionales, como los bares, restaurantes, locutorios, peluquería, frutería, que vemos en Cosas que dejé en la Habana, I love you baby y Princesas. Constatamos representaciones que evidencian la relación de esa población con los aspectos culturales caracte- 
rísticos de América Latina. Desde otra perspectiva, también encontramos representaciones que revelan negociaciones, asimilaciones y rechazos de aspectos de la cultura autóctona, como se refleja en Cosas que dejé en la Habana y en Flores de otro mundo. La construcción de los vínculos sociales y afectivos establecidos con redes de latinoamericanos y con redes de autóctonos también es explorada. La decisión de acceder al trabajo irregular también es percibida como una importante táctica para que los latinoamericanos sigan con sus proyectos. Además de esto, el matrimonio de conveniencia con un cónyuge español es contemplado como una institución social que puede facilitar la obtención de los documentos de residencia y trabajo y garantizar, por ejemplo, la realización del reagrupamiento familiar, como vemos en Flores de otro mundo, Sobreviviré y I love you baby.

La principal razón que impulsa a la población latinoamericana a llevar a cabo su proyecto migratorio es la búsqueda por la estabilidad económica. Sin embargo, entrevemos un conjunto de necesidades y deseos personales, como adquirir los documentos de residencia y trabajo; enviar remesas de dinero a sus familiares; acceder a una vivienda digna; regresar a sus países de origen; asentarse definitivamente en España; acomodarse profesionalmente; traer a los descendentes; disfrutar de la felicidad amorosa; formar una nueva familia. En estos relatos quedan evidente sus éxitos y sus fracasos; tanto las historias de los que pueden cumplir algunos de sus objetivos, como vemos en Flores de otro mundo, l love you baby y Sobreviviré, como las de aquellos que viven situaciones de mera sobrevivencia, como observamos en En la puta calle, Flores de otro mundo y Rabia.

\subsubsection{Sobre el sustrato ideológico de la muestra}

Es reseñable que el incremento de las imágenes cinematográficas vinculadas con este colectivo, a partir de la década de los noventa, enriqueció las estrategias de representación de lo latinoamericano en el cine nacional, convergiendo con la intensificación de las corrientes de inmigración latinoamericana, en España. Santaolalla (2005: 20), por ejemplo, afirma que a partir de la segunda mitad de la década de los ochenta los discursos que manifiestan la etnicidad hispanoamericana pasan a ser más frecuentes en el panorama filmico nacional, fruto de una reavivación de las conexiones culturales entre España y América Latina. Según la autora, el incremento de las imágenes cinematográficas de lo latinoamericano y su impacto en el imaginario español estarían relacionados con la reavivación discursiva de la memoria colonial en la década de los noventa, debido a la conmemoración del quinto centenario de la colonización española de América en 1992 y de la rememoración del quinto centenario por las pérdidas de Cuba, Puerto Rico y Filipinas en 1998.

Por otro lado, también vinculamos el alza de la inmigración latinoamericana en España con un conjunto de factores globales en el país de acogida, como la in- 
corporación del país en la Unión Europea en la década de los ochenta, la superación de la crisis económica, el incremento veloz del sector servicios, la caída de las tasas de natalidad en una sociedad de bienestar, el incremento progresivo de la población mayor y el déficit de la población activa (Juan B. Vilar, 2002: 14), además de otros aspectos, como el fortalecimiento de los lazos históricos, culturales y económicos entre la ex metrópoli y la ex colonia, y una serie de decisiones en materia de política migratoria, como por ejemplo, la firma de los convenios bilaterales y de doble nacionalidad, la adquisición de la nacionalidad española, y la obtención del permiso de residencia y trabajo (García Ballesteros, Jiménez Basco y Redondo González, 2009: 68).

También podemos destacar el rasgo militante de un cine que denuncia problemáticas culturales y socio-económicas, como la ausencia de cohesión y las situaciones de discriminación étnica y social, marginación y exclusión que pueden experimentar las comunidades inmigrantes latinoamericanas, en España. Así, el corpus filmico llama la atención sobre la importancia de los derechos, la igualdad y la ciudadanía de esta minoría étnica, reflejando sobre la falta de ciertos valores humanos con que la sociedad de acogida puede llegar a recibir a los colectivos más vulnerables, mostrando la ausencia de respeto, tolerancia y alteridad de ciertos grupos sociales autóctonos, y la inexistencia de conocimientos sobre la otredad latinoamericana. De este modo, vemos como estas películas se incluyen en un panorama cinematográfico que pasa a interesarse por los conflictos sociales presentes en el fenómeno de la inmigración económica, a través de un enfoque realista, con el empeño de denunciar la pobreza, el racismo, la explotación laboral, el desarraigo, los conflictos de integración, la soledad y las carencias afectivas que experimentan las minorías étnicas provenientes del tercer mundo, en las sociedades en proceso de evolución multicultural, como destaca Sánchez Noriega (2002: 85).

Esta investigación evidencia algunas contradicciones presentes en las imágenes, ya que identificamos que la producción cinematográfica española más reciente también sigue operando en la construcción ideológica de lo que serían los pueblos latinoamericanos, desde un punto de vista neocolonialista. Como vimos, algunas de esas representaciones no exploran las diferencias de la «otredad» étnica, cultural e histórica latinoamericana. Las imágenes poco variadas homogeneizan y distorsionan sus conductas, movilidad urbana, rasgos de personalidad y características físicas, lenguas y dialectos, creencias religiosas, costumbres y tradiciones culturales, contribuyendo para la propagación de modelos de identidades marcadas por el estereotipo. Vemos que esta estrategia discriminatoria fomenta la jerarquía social y el menosprecio de las «otredades» latinoamericanas, y normaliza las relaciones sociales y culturales de poder entre España y América Latina.

De acuerdo con Bhabha (2002: 95,96), el estereotipo sería la manifestación discursiva del concepto de «fijeza»; una estrategia en la que vemos la construcción 
de un repertorio de relaciones ambivalentes en que el sujeto colonizador no reconoce la alteridad del sujeto colonizado a través de la repetición de una red de conocimientos invariables y predictibles que no necesitan ser probados para que se constituyan en autoridad. Como Bhabha (2002), Shohat y Stam (2002) también detectan que a pesar de haberse decretado oficialmente el fin de la doctrina colonial europea, que empieza a partir de las expansiones internas de Europa, en el siglo XI, la presencia de un residuo discursivo eurocéntrico, de característica neocolonialista, seguiría siendo emanado y reforzado en la actualidad por ciertas prácticas y representaciones contemporáneas. El sistema colonial ha dejado secuelas en la cultura y en la esfera del cotidiano, propagando modelos hegemónicos, dogmáticos, fijos y distorsionados, y asociando la cultura del colonizado con la ausencia de valores, ética y estética (Fanon, 1968:35-36). Por otro lado, al acercarse a los regímenes dominantes de representación, Hall (2010) detecta cómo las otredades étnicas fueron estereotipadas y fetichizadas en los discursos estéticos y culturales occidentales, emanando mensajes racistas. De acuerdo con el autor, el discurso racista construye fronteras simbólicas entre las categorías raciales y los sistemas binarios de representación, que definen los lugares de pertenencia y otredad de los sujetos, pues «(..) A lo largo de esta frontera surge lo que Gayatri Spivak (1987) llama la «violencia epistémica» de lo exótico, lo primitivo, lo antropológico y lo folclórico (...)» (Spivak apud Hall, 2010:309)

Se evidencia que estas películas ignoran mayoritariamente algunos de los impactos desastrosos que la doctrina colonialista dejó en las sociedades latinoamericanas contemporáneas y que se relacionan con los fenómenos migratorios más recientes. En lo tocante a este tema, mencionamos la dominación técnico-informativo-cultural, política, económica y ambiental; la diseminación de discursos y prácticas eurocéntricas y racistas; el subdesarrollo socio-económico del continente; y la vulnerabilidad social de las poblaciones autóctonas y las afro descendentes. Añadimos que la ausencia de imágenes que hacen referencia al mestizaje entre las etnias nativas, africanas y europeas expresan el poco interés que tiene este cine de reflejar las diferencias socio-políticas y las riquezas de los elementos históricos, culturales, artísticos, étnicos, lingüísticos y religiosos que distinguen esas culturas, a pesar de que posean una historia en común.

Aunque hemos visto que en la mayoría del corpus filmico exista una propensión a revisitar ciertos modelos estigmatizados, vale la pena mencionar que también identificamos algunos discursos que rompen con esta tendencia, pues abordan temáticas originales y reflejan un discurso más plural, como vemos en Ander, que trata de la sexualidad y de la etnicidad; en En la puta calle, que alude el tema de las relaciones coloniales entre España y Latinoamérica; en Cosas que dejé en La Habana, que trae la historia de Nena, un personaje que se aleja de los tópicos que suelen caracterizar las representaciones femeninas; y en Rabia, que refleja las problemáticas sociales de la experiencia de la inmigración, a través del recurso del suspense. 


\section{Consideraciones finales}

Por consiguiente, de acuerdo con los preceptos teóricos de Sorlin (1985), concluimos que las contribuciones teóricas de diversas disciplinas sirven como instrumentos fundamentales capaces de aproximarnos a la inmigración procedente de América Latina y de reflexionar sobre el material filmico que enfoca este fenómeno. Podemos utilizar las imágenes cinematográficas globales como documento histórico y socio-cultural, pero siempre que haya un diálogo con otras producciones intelectuales. Observamos que el cine de este período, a pesar de estar estrechamente conectado con muchas de las características socio-demográficas de la época, no es un retrato fidedigno de los inmigrantes latinoamericanos en España, ya que emite una trasposición ficcional de las estructuras sociales de estas otredades. Vimos que las películas son fragmentos del mundo circundante, regidas por ciertas reglas de selección de lo real, a través de las propias limitaciones ideológicas. Por eso el cine se convierte en una herramienta para conocer un contexto socio-cultural concreto e interpretar las percepciones, las inquietudes, las creencias, los valores morales, los prejuicios comunes y los discursos de poder de una época.

Constatamos que el cine es un artefacto que puede vehicular formas de representación estigmatizadas pero, a la vez, también puede incitar otros discursos sobre la representación cinematográfica de las poblaciones provenientes de América Latina en España. Las imágenes pueden ser contempladas como un dispositivo que capaz de «descolonizar» las representaciones; denunciar las problemáticas sociales, culturales y políticas presentes en los fenómenos migratorios; considerar la complejidad de los procesos de las minorías en términos igualitarios; y desafiar los modelos de identidad cultural, étnica e histórica característicos de una sociedad neocolonialista, ya que este sistema tiende a remodelar nuestras subjetividades y modos de relacionarnos con los demás, a través de prácticas y discursos hegemónicos.

\section{Anexo. Muestra global de películas}

En la puta calle (Enrique Gabriel, 1996)

Demasiado caliente para ti (Javier Elorrieta, 1996)

Sabor latino (Pedro Carvajal, 1997)

Cosas que dejé en la Habana (Manuel Gutiérrez, 1997)

Airbag (Juanma Bajo Ulloa, 1997)

El grito en el cielo (Félix Sabroso y Dunia Ayaso,1998)

Flores de otro mundo (Icíar Bollaín, 1999)

Sobreviviré (Alfonso Albacete y David Menkes, 1999)

Pídele cuentas al rey (José Antonio Quirós, 1999) 
Adiós con el corazón (José Luis García Sánchez, 2000)

Me da igual (David Gordon, 2000)

I love you baby (Alfonso Albacete y David Menkes, 2001)

Solo mía (Javier Balaguer, 2001)

Lugares comunes (Adolfo Aristarain, 2002)

Piedras (Ramón Salazar, 2002)

La novia de Lázaro (Fernando Merinero, 2002)

La flaqueza del bolchevique (Manuel Martín Cuenca, 2003)

Tiempo de tormenta (Pedro Olea, 2003)

El regalo de Silvia (Dionisio Pérez, 2003)

El 7. día (Carlos Saura, 2004)

XXL (Julio Sánchez Valdés, 2004)

Cosas que hace que la vida valga la pena (Manuel Gómez Pereira, 2004)

Princesas (Fernando León de Aranoa, 2005)

Agua con sal (Debajo de las piedras) (Pedro Pérez Rosado, 2005)

Segundo asalto (Daniel Cebrián, 2005)

La noche del hermano (Santiago García de Leániz, 2005)

Reinas (Manuel Gómez Pereira, 2005)

Malas temporadas (Manuel Martín Cuenca, 2005)

Tapas (Juan Cruz y José Corbacho, 2005)

Sinfonía de Ilegales (José Luis de Damas, 2005)

El próximo oriente (Fernando Colomo, 2006)

Volver (Pedro Almodóvar, 2006)

Locos por el sexo (Javier Rebollo, 2006)

La distancia (Iñaki Dorronsoro, 2006)

La torre de Suso (Tomás Fernández, 2007)

Abrígate (Ramón Costafreda, 2007)

Mataharis (Icíar Bollaín, 2007)

Pudor (David Ulloa y Tristán Ulloa, 2007)

7 Mesas (de billar francés) (Gracia Quejereta, 2007)

El norte (entre el infinito y la nada) (Lino Varela, 2007)

Atasco en la nacional (Josetxo San Mateo, 2007)

Cobardes (José Corbacho y Juan Cruz, 2008)

Pájaros Muertos (Guillermo Sempere y Jorge Sempere, 2008)

Ander (Roberto Castón, 2009) 
Mentiras y gordas (Alfonso Albacete y David Menkes, 2009)

Pagafantas (Borja Cobeaga, 2009)

Rabia (Sebastián Cordero, 2010)

Amigos... (Marcos Cabotá y Borja Manso, 2011)

\section{Referencias bibliográficas}

Bhabha, H.K. (2002). El lugar de la Cultura. Buenos Aires: Manantial.

Elena, A. (2005). «Latinoamericanos en el cine español: Los nuevos flujos migratorios, 19752005». En Secuencias, n. ${ }^{\circ} 22$, pp. 197-135.

Fanon, F. (1968). Piel negra, máscaras blancas. La Habana: Instituto del Libro.

García Ballesteros, A., Jiménez Basco, B., Redondo González, A. (2009). «La inmigración latinoamericana en España en el siglo XXI». En Investigaciones Geográficas, Boletín del Instituto de Geografía. UNAM, Núm. 70, pp.56-70.

Göttsch, M. (2010). «Inmigración latinoamericana en España. El estado de la investigación». En Ayuso, A., Pinyol, G. (Ed.). Inmigración latinoamericana en España. El estado de la investigación. Barcelona: Fundación CIDOB, pp. 279-330.

Hall, S. (2010). «Nuevas etnicidades. En Hall, S., Sin garantías: trayectorias y problemáticas en estudios culturales. Popayán, Lima, Bogotá, Quito: Envión Editores, Instituto de Estudios Peruanos, Universidad Andina Simón Bolívar, Sede Ecuador, pp. 305-314.

Monterde, J.E. (2008). El sueño de Europa. Cine y migraciones desde el Sur. Granada, Madrid: Consejería de Cultura de la Junta de Andalucía, Festival de Granada-Cines del Sur, Ocho y Medio.

Sánchez Noriega, J.L. (2002). «Tematizaciones y tratamientos en las representaciones filmicas de los conflictos sociales». En Camarero, G. (Ed.), La mirada que habla (cine e ideologías). Madrid: Akal, pp. 79-88.

Santaolalla, I. (2005). Los «Otros»: Etnicidad y «raza» en el cine español contemporáneo, Zaragoza, Madrid, Prensas Universitarias de Zaragoza, Ocho y Medio.

Sorlin, P. (1985, 1996). Sociología del cine. La apertura para la historia de mañana. México: Fondo de Cultura Económica; Cines europeos, sociedades europeas, 1939-1990. Barcelona: Paidós.

Tedesco, L. (2010). «Latinoamericanos en España: de la integración al retorno». En Ayuso, A., Pinyol, G. (Eds.), Inmigración latinoamericana en España. El estado de la investigación. Barcelona: Fundación CIDOB, pp. 119-136.

Vilar, J.B. (2002). «Inmigración actual en España y ley de extranjería». En Anales de Historia Contemporánea, n. ${ }^{\circ} 18$, pp. 13-18. 